\title{
Potential impact of some soil borne fungi on biodegradation of some organophosphorous nematicides
}

\author{
Tamer M. A. Thabit ${ }^{1,2, ~ *, ~ M e d h a t ~ A . ~ H . ~ E l-N a g g a r ~}{ }^{2,3}$ \\ ${ }^{1}$ Central Agric, Pesticides Lab. (CAPL) Agric, Research Center, Giza, Egypt \\ ${ }^{2}$ Central Lab. of Research, Grain Silos \& Flour Mills Org. (GSFMO) B.O. Box 3402Riyadh 11471, KSA \\ ${ }^{3}$ Plant Pathology Research Institute, Agric, Research Center, Giza, Egypt
}

\section{Email address:}

Medhat14@yahoo.com (El-Naggar M. A.)

\section{To cite this article:}

Tamer M. A. Thabit, Medhat A. H. El-Naggar. Potential Impact of Some Soil Borne Fungi on Biodegradation of Some Organophosphorous Nematicides. American Journal of Environmental Protection. Vol. 3, No. 6, 2014, pp. 299-304. doi: 10.11648/j.ajep.20140306.11

\begin{abstract}
Organophosphorous nematicides are highly toxic pesticides used to control nematodes in agriculture soil. An in vitro Biodegradation study was conducted to determine the biodegradability of, ethoprophos, fenamiphos and triazophos nematicides, using fungi strains isolated from sandy agriculture soil under date palm trees. Five fungi strains labeled as S1 (Fusarium oxysporum), S2(Aspergillus flavus), S3 (Aspergillus fumigatus), S4 (Fusarium moniliforme) and S5 (Trichothecium roseum) were isolated and identified, then incubated with nematicides at successive intervals untill 45 days in liquid medium paralleled with control samples. Recovery rates were performed at two levels 0.1 and $1 \mathrm{mg} \mathrm{kg}^{-1}$, values were over $90 \%$ for all nematicides. Limit of detection values (LOD) were $0.010,0.012$ and $0.011 \mathrm{mg} \mathrm{kg}^{-1}$ and limit of quantitation values (LOQ) were $0.033,0.040$ and $0.036 \mathrm{mg} \mathrm{kg}^{-1}$ respectively. Data indicated that $\mathrm{S} 1$ (Fusarium oxysporum) and S2 (Aspergillus flavus) accelerated the degradation rate of all mentioned nematicise, and S2 had the highest impact more than S1, while the other strains had no significant effect. Half-life values $\left(\mathrm{RL}_{50}\right)$ for nematicides with $\mathrm{S} 1$ were $18.15,16.65$ and 15.24 days, respectively, and with S2 were 10.35, 13.87 and 11.18 days, respectively, while control values were 26.30, 24.28 and 26.70 days, respectively.
\end{abstract}

Keywords: Biodegradation, Organophosphorous, Nematicides, Agricultural Soil, Soilborne Fungi

\section{Introduction}

Pesticides play an important role in success of modern farming and food production. However, one of the major environmental problems is the release of pesticides into the environment causing contaminated air, soil and ground water. Due to environmental concerns associated with the accumulation of pesticides in environment and food products there is a great need to develop safe, convenient and economically feasible methods for pesticide remediation (Zhang and Quiao, 2002). Due to the magnitude of this problem, which became a big challenge facing the entire world today, several biological techniques involving biodegradation of organic compounds by microorganisms have been developed (Schoefs et al., 2004). The utilizing of microorganisms (fungi or bacteria), either naturally occurring or introduced, to degrade pollutants is called bioremediation (Pointing, 2001). Bioremediation is a rapid, inexpensive, effective and ecologically safe method has been emerged as a cleanup method for the environmental components. The basis for bioremediation, is the degrading microorganisms obtain $\mathrm{C}$, $\mathrm{N}$ or energy from pesticide molecules and convert organopollutants to carbon dioxide. From an environmental point of view this total conversion is desirable as it represents complete detoxification (Gan and Koskinen, 1998). Fungal bioremediation, which also known as mycoremediation, considered promising process in environmental decontamination field, whereas many fungi from various genus and species have been proved to be able to decompose many types of organo-pollutants included pesticides and degrade it to non-toxic compounds, but till the moment this process still under examination and untapped widely (Singh, 2006 and Harms et al., 2011). Organophosphorous nematicides are highly toxic pesticides used to control nematodes in agriculture soil. Ethoprophos, fenamiphos and triazophos are common used organophosphorous nematicides 
characterized by the high persistance and toxicity, used to control different types of nematodes in a wide range of crops and ornamentals (Tomlin, 2006). Object of this work is to study the impact of some fungi isolated from agricultural soil on biodegradation of mentioned nematicides. Five broadly spread fungi strains were isolated, purified and identified from soil under date palm trees, then used in an in vitro trial to estimate their effect on the biodegradation rate of tested nematicides to give a primary indication about pesticide mycodegradation and soil mycoremediation.

\section{Materials and Methods}

\subsection{Soil Samples Collection and Preparation}

Agriculture soil samples were collected from rhizosphere layer of date palm trees for many dry and semi dry varieties spreaded in farms around great Cairo area over the year of 2012. Samples were taken randomly from till $30 \mathrm{~cm}$ around trees and till 10 of depth. Samples were air dried aseptically for 3 days at room temperature to reduce the bacterial flora and avoid any harm to the fungal growth (Korn-Wendisch and Kutzner, 1992).

\subsection{Fungi Isolation and Identification}

One gram of prepared soil was shaken in a flask containing $99 \mathrm{~mL}$ of distilled water, and serial dilutions were carried out and inoculated on starch casein solid medium (Kuster and Williams, 1964). Plates were incubated at $25 \pm 2{ }^{\circ} \mathrm{C}$ until the sporulation of fungal colonies occurred. Colonies (where mycelia remained intact and the aerial mycelia and long spore chains were abundant) were picked up and transferred to starch nitrate medium (Lechevalier and Lechevalier, 1970). The developed fungi were purified using hyphal tips or the single-spore technique and then transferred to slant potato dextrose agar medium. The purified fungi were verified, then five common fungi strains were selected and identified according to the procedures of Barnett (1960), Subramanian (1971), and Tousson and Nelson (1976). Pure cultures of fungi were obtained from selected colonies for repeated subculturing. An agar disk of a grown fungus cultures were removed aseptically and placed on a Biolog universal growth medium plate, the incubation extended for 48 hours at $25 \pm 2$ ${ }^{\circ} \mathrm{C}$ and then identified by the Biolog system according to Smalla et al. (1998)., using Biolog plate type (FF). However, they have been developed especially for studies of plant and human pathogens as discribed by Biolog Inc. Not only the substrates on FF plates differ from those on the GN and GP plates but also the tetrazolium dye is modified, so it can be metabolized by fungi. With FF plates both the formazan production (connected with the amount of utilized substrate) and the turbidity of a solution in plate wells (connected with the hyphae growth) are measured according to Stefanowicz (2006).

Isolates were tested to make sure of their inability to secrete any of the known mycotoxins such as Aflatoxins, Fumonisins, Zearalenone, T-2, ochratoxin, patulin,
Citreoviridin and Deoxynivalenol. The examination has been testing for the detection of toxins using the method of Stubblefield et al. (1988), Christian, (1990) and Geraldo et al., (2006).

\subsection{Pesticide Working Samples Preparation}

Known concentration of ethoprophos, fenamiphos and triazophos active ingredients (a.i.), from Dr. Ehrenstorfer Reference Materials, Germany were used for standard solution preparation in ethyl acetate. Working samples were prepared as 5 ug of each a.i / $1 \mathrm{ml}$ liquid medium, then has been spread in a culture tubes, solvent was evaporated using pure nitrogen gas. Biolog Universal Growth Agar medium (BUG) pure liquid medium (57 $\mathrm{g} \mathrm{l}^{-1}$ purified water), $\mathrm{PH} 7.3 \pm$ 0.1 was added $(10 \mathrm{ml})$, an agar disk of pure selected and identified fungi strains were inoculated each separately, tubes were shaken for $30 \mathrm{~min}$, then incubated at $29 \pm 2{ }^{\circ} \mathrm{C}$. Samples were taken at successive intervals after incubation at zero, 6 hours, $1,3,7,10,15,25,35$ and 45 days paralleled with control samples at each interval, zero time is the initial concentration directly before incubation $(50 \mathrm{ug})$.

\subsection{Residues Extraction and Cleaning Up Procedures}

Solid Phase Extraction (SPE) technique was used for extraction and cleaning-up for pesticide residues from the liquid medium after volume modifications of the procedure mentioned by López-Blanco et al. (2006). CUPSA3 SPE cartridge $\left(\mathrm{C} 18+\mathrm{n}-2\right.$ aminoethyl, $\left.100 \mathrm{mg} \mathrm{ml}^{-1}\right)$ from United Chemical Technologies (UCT), USA, was conditioned with ethyl acetate $(5 \mathrm{~mL})$ followed by methanol $(5 \mathrm{~mL})$ and ultrapure water $(5 \mathrm{~mL})$ at rate of $3 \mathrm{ml} \mathrm{min}^{-1}$, without allowing the cartridge to dry out. The aqueous sample $(10 \mathrm{~mL})$ was loaded on and passed thru the cartridge at rate of $0.8 \mathrm{ml} \mathrm{min}^{-1}$ (sample should be filtered before loading to remove suspended and insoluble materials of fungi). Cartridge was dried by pure nitrogen gas over surface for 2 min. Adsorbed pesticides were eluted by ethyl acetate $(5 \mathrm{~mL})$. Rapid Trace SPE workstation from Zymark, Caliper Life Sciences was used for SPE handling, solvents used were HPLC grade, from BDH chemicals, UK. Agilent 7890A gas chromatography equipped with nitrogen-phosphorus detector (NPD) and HP-5 capillary column $(30 \mathrm{~m} \times 320 \mathrm{um} \times 0.25$ um) from J\&W Scientific was used for pesticide residue analysis, injector at $260{ }^{\circ} \mathrm{C}$, splitless mode, detector at $320{ }^{\circ} \mathrm{C}$, ignition gases were $\mathrm{H}_{2}$ at $3 \mathrm{ml} \mathrm{min}^{-1}$ and air at $45 \mathrm{ml}$ $\mathrm{min}^{-1}$. Oven programmed at $160{ }^{\circ} \mathrm{C}$ for $3 \mathrm{~min}$, ramped at $20{ }^{\circ} \mathrm{C} \min ^{-1}$ to $270{ }^{\circ} \mathrm{C}$ and held for 2 min., carrier gas $\mathrm{N}_{2}$ at flow rate $3 \mathrm{ml} \mathrm{min}{ }^{-1}$ with total run time $10.50 \mathrm{~min}$. Retention time was (Rt) was 3.95, 7.32 and $8.05 \mathrm{~min}$. for ethoprophos, fenamiphos and triazophos, respectively.

\subsection{Method Validation Studies}

Freshly prepared stock solution Standard of each nematicide (400 ng $\mu \mathrm{l}^{-1}$ ) in ethyl acetate was used for calibration and calculation. working standards at 1, 2, 5, 10 and $20 \mathrm{mg} \mathrm{l}^{-1}$ were prepared, then $10 \mathrm{ml}$ of untreated liquid 
media has been spiked. Recovery rate was performed using untreated liquid media, spiked with nematicides a.i., solution at two levels 0.1 and one $\mathrm{mg} \mathrm{kg}^{-1}$, then procedures of all entire method were performed, values were over $90 \%$ for all studied nematicide as shown in Table 1. Values of the limit of detection (LOD) and limit of quantitation (LOQ) of the analytical method used were estimated from the following equations as clarified in ICH (1996), which.

$$
\mathrm{LOD}=\frac{3.3 \mathrm{Sd}}{\mathrm{b}}, \mathrm{LOQ}=\frac{10 \mathrm{Sd}}{\mathrm{b}}
$$

LOD: limit of detection

LOQ: limit of quantitation

Sd: Standard deviation of calibration curve response (residual standard deviation)

b: Slope of calibration curve

\subsection{Kinetic studies}

The degradation rate of diazinon was calculated mathematically according to Timme and Frehse (1980), that degradation behavior of pesticide residues can be described mathematically as a pseudo-first order reaction, rate of degradation $(\mathrm{K})$ could be calculated using common logarithms from the following equation:-

$$
\log \mathrm{R}=\log \mathrm{R}_{0}-0.434 \mathrm{Kt}
$$

$\mathrm{R}_{0}$ : residue level at the initial time (zero time), $\mathrm{R}$ : residue level at interval in days after application.

$\mathrm{Kt}$ : degradation rate constant at the successive intervals in days, $\mathrm{K}$ : mean of $\mathrm{Kt}$

Diazinon half-life value $\left(\mathrm{RL}_{50}\right)$ was calculated mathematically according to Moye et al. (1987) from the following equation:-

$$
\mathrm{RL}_{50}=\frac{\mathrm{Ln} 2}{\mathrm{~K}}
$$

\subsection{Statistical Analysis}

T-test was used for analyzing the obtained data statistically to define the significance levels with the basis outlined by Snedecor and Cochran (1967).

\section{Results}

\subsection{Fungi Strains Identification}

All selected fungi strains from the division of Ascomycota, Table 2 shows the identification and colony shape of fungi strains isolated from the agricultural soil. S1 (Fusarium oxysporum), Colonies are initially white, become tinged with salmon and lavender at maturity, Lavender to purple reverse, Salmon to orange. Sporodochia may be present. Conidiophores are short (when contrasted with those of $F$. solani). Macroconidia usually produced abundantly, slightly sickle-shaped, thin-walled, with an attenuated apical cell and a foot-shaped basal cell. S2 (Aspergillus flavus), Colonies are olive to lime green with a cream reverse, rapid growth, texture is woolly to cottony to somewhat granular. Sclerotia when present are dark brown. A clear to pale brown exudate may be present in some isolates. Hyphae are septate and hyaline. Conidial heads are radiate to loosely columnar with

\begin{tabular}{|c|c|c|c|c|}
\hline \multirow{2}{*}{ Pesticide } & \multicolumn{2}{|c|}{ Recovery \% } & \multirow{2}{*}{ LOD (ppm) } & \multirow{2}{*}{ LOQ (ppm) } \\
\hline & 0.1 ppm & 1 ppm & & \\
\hline Ethoprophos & $90.14 \pm 1.08$ & $98.94 \pm 1.55$ & 0.010 & 0.033 \\
\hline Fenamiphos & $93.39 \pm 1.28$ & $102.18 \pm 2.47$ & 0.012 & 0.04 \\
\hline Triazophos & $91.22 \pm 1.13$ & $100.22 \pm 1.89$ & 0.011 & 0.036 \\
\hline
\end{tabular}
age. Conidiophores are coarsely roughened, uncolored.

Table 1. Recovery percentages, $L O D$ and $L O Q$ values of tested pesticides

LOD: Limit of Detection, LOQ: Limit of Quantitation

Table 2. Identification and colony shape of isolated fungi

\begin{tabular}{ll}
\hline Strain & Fungi name \\
\hline S-1 & Fusarium oxysporum \\
S-2 & Aspergillus flavus \\
S-3 & Aspergillus fumigatus \\
& \\
S-4 & Fusarium moniliforme \\
&
\end{tabular}

S3 (Aspergillus fumigatus), Colonies are smoky graygreen with a slight yellow reverse. Some isolates may display a lavender diffusible pigment. Very mature colonies turn slate gray, rapid growth, texture is woolly to cottony to somewhat granular. Atypical isolates may remain white with little conidiation. Hyphae are septate and hyaline. Conidial heads are strongly columnar in an undisturbed culture. Conidiophores are smooth-walled, uncolored. S4 (Fusarium moniliforme), Macroscopic morphology may vary significantly on different media, and descriptions here are based upon growth on potato flakes agar (PFA) at $25{ }^{\circ} \mathrm{C}$. Colonies initially white become tinged with lavender or 
colorless to dark purple reverse. Sporodochia, when formed are cream to orange, however are generally sparse on PFA. Dark blue sclerotia may be present. Hyphae are septate and hyaline. Conidiophores are medium length simple or branched (shorter than in F. solani and longer than those seen in F. oxysporum). S5 (Trichothecium roseum), it is a spread wide and often isolated from decaying plant substrates, soil, seeds of corn, and foodstuffs (especially flour products). Colonies are moderately fast growing, flat, suede-like to powdery, initially white become rosy, pink or orange with age. The conidiophores are indistinguishable from the vegetative hyphae until the first conidium is produced. It is erect, unbranched, often septate near the base. The conidiophore is progressively shortened with the formation of each conidium.

\subsection{Pesticide Residues and Degradation Rate}

Data in Table 3 and Figures 1, 2 and 3 show degradation rate and residue half-life values of tested nematicides with tested fungi strains comparing to control treatment. Data revealed that residue half-life values (RL50) of ethoprophos, fenamiphos and triazophos with S1 (Fusarium oxysporum) were 18.15, 16.65 and 15.24 days respectively, while with S2 (Aspergillus flavus) were 10.35, 13.87 and 11.18 days, with S3 (Aspergillus fumigatus) were 21.70, 24.53 and 24.74 days, respectively, with S4 (Fusarium moniliforme) were 23.73, 25.94 and 25.91 days, respectively and with S5 (Trichothecium roseum) values were 21.10, 25.95 and 25.10 days, respectively. RL50 values for control treatments were 26.30, 24.28 and 26.70 days for tested nematicides, respectively.

Table 3. Degradation rates of tested nematicides against control (K and RL50 values)

\begin{tabular}{|c|c|c|c|c|c|c|}
\hline \multirow{3}{*}{ Fungi Strains } & \multicolumn{6}{|c|}{ Degradation rate \& RL50 } \\
\hline & \multicolumn{2}{|c|}{ Ethoprophos } & \multicolumn{2}{|c|}{ Fenamiphos } & \multicolumn{2}{|c|}{ Triazophos } \\
\hline & $\mathbf{K}$ & RL50 (Days) & $\mathbf{K}$ & RL50 (Days) & $\mathbf{K}$ & RL50 (Days) \\
\hline Control & 0.0263 & 26.30 & 0.0286 & 24.28 & 0.0260 & 26.70 \\
\hline S1 & 0.0381 & 18.15 & 0.0417 & 16.65 & 0.0456 & 15.24 \\
\hline S2 & 0.0669 & 10.35 & 0.0410 & 13.87 & 0.0621 & 11.18 \\
\hline S3 & 0.0319 & 21.70 & 0.0283 & 24.53 & 0.0281 & 24.74 \\
\hline S4 & 0.0292 & 23.73 & 0.0268 & 25.94 & 0.0268 & 25.91 \\
\hline
\end{tabular}

K: Degradation rate constant, RL50: Residue Half-life value

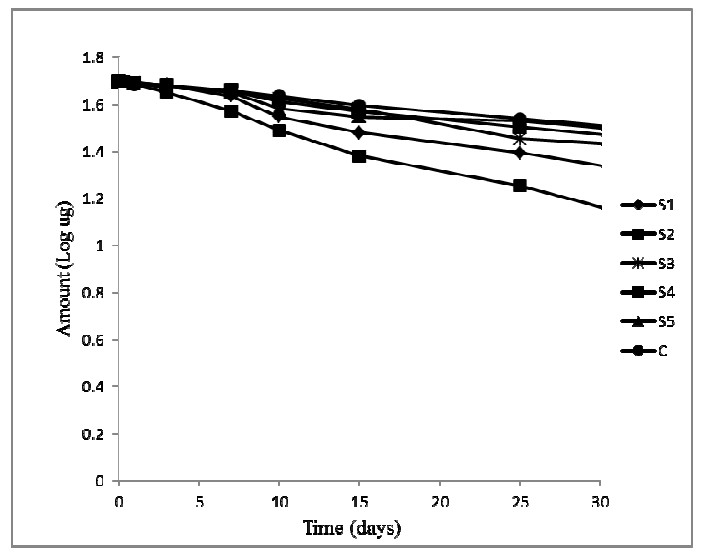

Figure 1. Ethoprophos degradation rate by tested fungi strains

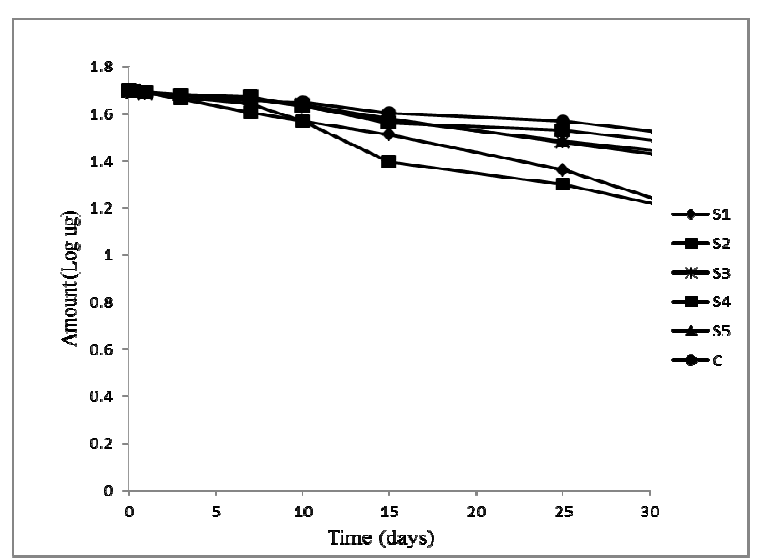

Figure 2. Fenamiphos degradation rate by tested fungi strains

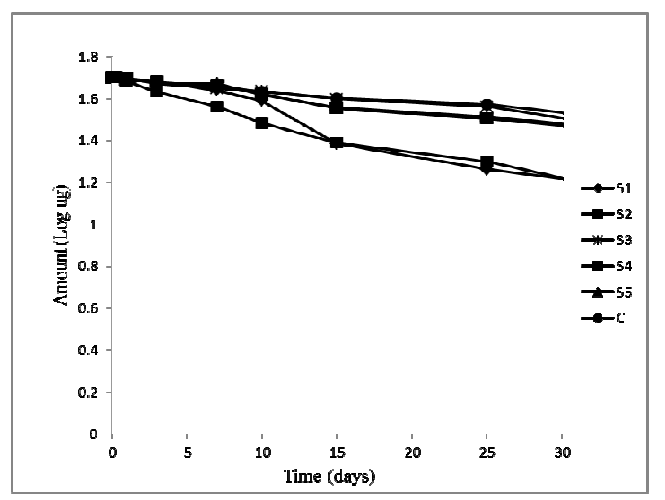

Figure 3. Triazophos degradation rate by tested fungi strains

Table 4. Statistical analysis results according to t-test $(p<0.05)$

\begin{tabular}{lccc}
\hline \multirow{2}{*}{ Fungi Strains } & \multicolumn{3}{c}{ t-test at $\mathbf{p}<\mathbf{0 . 0 5}$ for treatments } \\
\cline { 2 - 4 } & Ethoprophos & Fenamiphos & Triazophos \\
\hline S1 & 0.0153 & 0.0110 & 0.0239 \\
S2 & 0.0053 & 0.0107 & 0.0035 \\
S3 & 0.2417 & 0.0835 & 0.1010 \\
S4 & 0.3973 & 0.1185 & 0.0639 \\
S5 & 0.3281 & 0.0615 & 0.0751 \\
\hline
\end{tabular}

Data in Table 4 shows the results of statistical analysis using t-test at probability level $(\mathrm{p})<0.05$. Result indicated that S1 (Fusarium oxysporum) and S2 (Aspergillus flavus) the only two strains from all tested strains which accelerated the degradation rate of all mentioned nematicise which means that $\mathrm{p}$ values for $\mathrm{S} 1$ and $\mathrm{S} 2$ were lower than 0.05 , and S2 had the highest impact more than S1, P values for ethoprophos, fenamiphos and triazophos with S1 (Fusarium 
oxysporum) were $0.0153,0.0110$ and 0.0239 while with S2 (Aspergillus flavus) were 0.0053, 0.0107 and 0.0035, respectively while other strains had no significant effect when paired with control treatments, which means that $p$ values for S3, S4 and S5 were greater than 0.05 .

\section{Discussion}

Bioremediation is considered more environmentally friend than conventional remediation techniques and considered a green technology as it only depends on biological organisms and processes. It does not require any chemical addition or heating treatment however, it is still not spread widely and have not always yielded satisfactory results, nevertheless bioremediation is a very promising biotechnology (Juwarkar et al., 2010). It also has some limitations whereas some chemicals are not readily susceptible to biological degradation due to their chemical properties or strong sorption to the environmental matrix, or microbial degradation of some compounds may yield metabolites which are more toxic than the parent compound, or the long term scientific studies required to discover the best microorganisms for the job (Boopathy, 2000). Utilizing of fungi in bioremediation till the moment still under examination and untapped widely (Harms et al., 2011), while bioremediation studies mostly focuse on bactrial more than fungal bioremedation inspite of the incredible diversity of fungi which estimated around 1.5 million species (Hawksworth, 1991, 2001), fall under Kingdom of Fungi which is divided into three major classes: the zygomycetes, the ascomycetes and the basidiomycetes as reported by Carlile et al. (2001).

In this study, five strains of fungi have been selected and identified which were common spread in the tested samples and their inability to secrete any kind of the known mycotoxins has been confirmed which is considered very critical parameter in fungi strain selection for bioremediation job. Fusarium oxysporum (labeled as S1) and Aspergillus flavus (labeled as S2) were the only species had the ability to degrade the tested organophosphorous nematicides, ethoprophos, fenamiphos and triazophos, which significantly accelerated the degradation rate of all mentioned nematicides. S2 had the highest impact more than S1, however the other isolated strains had no significant effect on degradation rate of all studied nematicides. On the other hand, the other three strains did not significantly affect the degradation rate of tested nematicide. Many literatures has reported and proved similar results that the obtained results agreed with those obtained by Hasan (1999), which revealed that Fusarium oxysporum, Aspergillus flavus and Aspergillus sydowii had the ability to degrade some organophosphorous pesticides in soil when used as sole carbon source. Salama et al. (1999) also declared that Fusarium oxysporum and Rhizoctonia solani had the ability to degrade Pirimiphos methyl and carbaryl pesticides. Nyakundi et al. (2011) reported that some white rot fungal isolated from soil had the potential to degrade diazinon and methomyl insecticides and fungal mixtures in soil fasten the rate of biodegradation of pollutants much more than individual isolates.

From previous data, it is clear that fungi mostly degrade pesticides thru the utilization as sole carbon source thru the path of enzymatic hydrolysis. These findings may explain the role of soil fungi in pesticide degradation and open a new horizon to utilize soil fungi in pesticides degradation and environmental bioremediation on large scale

Some fungi species have the ability to secrete mycotoxins, which considered toxigenic fungus (pathogenic fungus), but not all isolates of the same species are toxigenic or pathogenic, which have the ability to secrete mycotoxins. Fusarium oxysporum (labeled as S1) and Aspergillus flavus (labeled as S2) species which known that they secrete mycotoxins (T2 and aflatoxin, respectively), but not all their isolates have the same ability (strains used in this work unable to secrete mycotoxins), as mentioned by Koehler et al., 1975.

\section{Conclusion}

Five fungi strains have been isolated and identified from the agricultural soil. Fusarium oxysporum (labeled as S1) and Aspergillus flavus (labeled as S2) showed the ability to degrade some organophosphorous nematicides such ethoprophos, fenamiphos and triazophos, which accelerated the degradation rate of all mentioned nematicides. S2 had the highest impact more than S1, however the other isolated strains had no significant effect on degradation rate of all studied nematicides.

\section{Acknowledgement}

Many thanks to Dr. Dalia I. H. El-Geddawy (Sugar Crop Res. Inst., Agric. Res. Center, Giza, Egypt) for review and revision of this article.

\section{References}

[1] Barnett, H.L. (1960): Illustrated Genera of Imperfect Fungi. In: Burgess Publishing Company, Minneapolis, Minnesota.

[2] Boopathy, R. (2000): Factors limiting bioremediation technologies. - Bioresource Technology 74: 63-67.

[3] Carlile, M. J., Watkinson, S. C., Gooday, G. W. (2001): The Fungi. - Elsevier Academic Press, London.

[4] Christian, G. (1990): HPLC tips and tricks. - Iden Press, Oxford.

[5] Gan, J., Koskinen, W.C. (1998): Pesticide fate and behaviour in soil at elevated concentrations. - In: Kearney, P.C. (ed.) Pesticide Remediation in Soils and Water. John Wiley \& Sons, Chichester.

[6] Geraldo, M. R. F., Tessmann, D. J., Kemmelmeier, C. (2006): Production of mycotoxins by Fusarium graminearum isolated from small cereals (wheat, triticale and barley) affected with scab disease in southern Brazil. - Brazilian Journal of Microbiology 37: 58-63. 
[7] Harms, H., Schlosser, D., Wick, L.Y. (2011): Untapped potential: exploiting fungi in bioremediation of hazardous chemicals. - Natural Reviews Microbiology 9: 177-192.

[8] Hasan, H. A. (1999): Fungal utilization of organophosphate pesticides and degradation by Aspergillus flavus and A. sydowii in soil. - Folia Microbiologica 44(1): 77-84.

[9] Hawksworth, D. L. (1991): The fungal dimension of biodiversity: magnitude, significance, and conservation. Mycological Research. 95: 641-655.

[10] Hawksworth, D. L. (2001): The magnitude of fungal diversity: the 1.5 million species estimate revisited. - Mycological Research 105: 1422-1432.

[11] ICH (1996): Validation of Analytical Procedure. International Conference on Harmonisation (ICH) of Technical Requirements for Registration of Pharmaceuticals for Human Use. - Methodology, Q2B, Geneva.

[12] Juwarkar, A., Singh, S., Mudhoo, A. (2010):. A comprehensive overview of elements in bioremediation. - Reviews in Environmental Science and Biotechnology 9: 215-288.

[13] Koehler, P. E., Hanlin, R. T., Beraha, L. (1975): Production of Aflatoxins B1 and G1 by Aspergillus flavus and Aspergillus parasiticus Isolated from Market Pecans. - American Society for Microbiology 30(4): 581-583.

[14] Korn-Wendisch, F., Kutzner, H.J. (1992): The family Streptomycetaceae. In the Procaryotes. - In: Balows, A., Truper H.G, Dworkin, M., Harder, W., Schleifer, K.H. (eds.). Springer-Verlag, New York.

[15] Kuster, E., Williams, S.T. (1964): Selection of media for isolation of streptomycetes. - Nature 202: 928-929.

[16] Lechevalier, M.P., Lechevalier, H. (1970): Chemical composition as a criterion in the classification of aerobic actinomycetes. - International journal of systematic bacteriology 20: 435-443.

[17] Lopez-Blanco, C., Gomez-Alvarez, S., Rey-Garrote, M., Cancho-Grande, B., Simal-Gandara, J. (2006): Determination of pesticides by solid phase extraction followed by gas chromatography with nitrogen-phosphorous detection in natural water and comparison with solvent drop microextraction. - Analytical and Bioanalytical Chemistry 384 1002-1006.

[18] Moye, H. A., Malagodi, M. H., Yoh, J., Leibee, G. L., Ku, C. C., Wislocki, P. G. (1987): Residues of avermectin B1a rotational crop and soils following soil treatment with (14C) avermectin B1a. - Journal of Agriculture and Food Chemistry 35: 859-864.
[19] Nyakundi, W. O., Magoma, G., Ochora, J., Nyende, A. B. (2011): Biodegradation of diazinon and methomyl pesticides by white rot fungi from selected horticultural farms in rift valley and central kenya. - Journal of Applied Technology in Environmental Sanitation 1 (2): 107-124.

[20] Pointing, S. (2001): Feasibility of bioremediation by white-rot fungi. - Applied Microbiology and Biotechnology 57: 20-33.

[21] Salama, A. K., Al-Mihanna, A. A., Abdalla, M. Y.(1999): Microbial degradation of pirimiphos-methyl and carbaryl by culture of two soil fungi. - Journal of King Saud University of Agricultural Science 11(1): 25-32.

[22] Schoefs, O., Perrier, M., Samson, R. (2004): Estimation of contaminant depletion in unsaturated soils using a reducedorder biodegradation model and carbon dioxide measurement. - Applied Microbiology and Biotechnology 64: 256-61.

[23] Singh, H. (2006): Mycoremediation: Fungal bioremediation. John Wi ley \& Sons Inc, New Jersey.

[24] Smalla, K., Wachtendorf, U., Heuer, H. (1998): Analysis of BIOLOG GN substrate utilization patterns by microbial communities. - Applied and Environmental Microbiology 64: 1220-1225.

[25] Snedecor, G. W., Cochran, W. G. (1967): Statistical methods 6th ed. - Press Ames, Iowa state University, Iowa.

[26] Stefanowicz, A. (2006): The Biolog Plates Technique as a Tool in Ecological Studies of Microbial Communities. Polish Journal of Environmental Studies 15(5): 669-676.

[27] Stubblefield, R. D., Greer, J. I., Shotwell, O. L. (1988): Liquid chromatographic method for determination of citreoviridin in corn and rice. - Journal of AOAC 71: 721-724.

[28] Subramanian, C.V. (1971): Hyphomycetes. - Indian Council of Agricultural Research, New Delhi.

[29] Timme, G., Frehse, H., (1980): Statistical interpretation and graphic representation of the degradation behaviour of pesticide residues. - Pflanzenschutz Nachrichten Bayer 33: 47-60.

[30] Tomlin, C. D. S., (2006): The Pesticide Manual. - 14th Ed. World Compendium, British Crop Protection Council (BCPC), Alton, Hampshire.

[31] Tousson, T.A, Nelson, P.E. (1976): A Pictorial Guide to the Identification of Fusarium Species according to the taxonomic system of Snyder and Hansen, 2 nd ed. - The Pennsylvania State University Press, University Park, Pennsylvania.

[32] Zhang, J., Chiao, C. (2002): Novel Approaches for remediation of pesticide pollutants. - International Journal Environment and Pollution 18(5): 423-433. 